\title{
Present and future utility of CT phenotypes in the assessment and management of COPD
}

Chronic obstructive pulmonary disease (COPD) is currently defined on the basis of spirometric evidence of airway obstruction in the setting of well-recognised risk factors. The Global Initiative for Obstructive Lung Disease (GOLD) system has been widely used to identify and classify the severity and risk predisposition of individual patients with COPD. However, individuals with identical GOLD stages have different morphologic appearances at computed tomography $(\mathrm{CT})$ which may reflect important differences in the underlying pathophysiology and genomic profile of COPD. ${ }^{[1]}$

A recent statement from the Fleischner Society ${ }^{[2]}$ described the phenotypic abnormalities recognisable at visual and quantitative evaluation of CT in subjects with COPD. Although CT is a wellvalidated tool to assess the presence, pattern and extent of emphysema, its role in COPD has not been clearly determined and is not routinely recommended. ${ }^{[3]}$ Subsequently, Ostridge and Wilkinson ${ }^{[4]}$ reported on the present and future utility of CT in the assessment and management of COPD. They highlight the visually defined and quantitative CT subtypes of COPD. These include emphysema, which may be centrilobular (CLE), panlobular (PLE) or paraseptal (PSE); airway disease such as bronchial or small airways disease; and other associated features (large airways disease, interstitial lung disease, pulmonary artery enlargement and bronchiectasis). 
CLE is characterised by small, well-defined areas of low attenuation surrounded by normal lung. Micro-CT scan of the primary lesion shows dilatation and destruction of proximal respiratory bronchioles with sparing of alveoli near lobular septa. This is the most common type of smoking-related emphysema and is usually upper-lung predominant. Quantifying the extent of CLE subcategorises it into mild, moderate and, in its most severe forms, confluent or advanced destructive emphysema. In the latter, CT confers the advantage of identifying patients who may benefit from lung volume reduction surgery, nonsurgical interventions (e.g. coils, valves, sealant and airway bypass) and bullectomy ${ }^{[5]}$ It is important to recognise that while the extent of CLE correlates well with histopathology, it often does not correspond with the GOLD classification for COPD. Furthermore, when quantified with densitometry, CT serves as a better predictive value for respiratory and cardiac mortality than GOLD staging. ${ }^{[6]}$ PLE specifically refers to diffuse emphysematous destruction across the entire lobule. It has been associated with alpha-1 antitrypsin deficiency and is often lower-lobe predominant. In general, the extent and severity of alveolar destruction in PLE is milder than that in CLE. PSE describes lesions located distal to the acinus near the pleural surface, which includes the fissures. PSE may occur together with CLE but when it occurs alone is often not associated with significant symptoms or physiological impairment. It is the most common type of emphysema associated with bullous lung disease and subsequent pneumothorax.

Bronchial wall thickening is commonly observed in heavy cigarette smokers, particularly those with chronic bronchitis, presumably because of bronchial inflammation and remodelling. ${ }^{[7]}$ Small airway disease is often the major cause of obstruction in COPD. ${ }^{[8]}$ It can occur as a primary expression of COPD and can be difficult to detect physiologically. CT can thus be helpful in identifying signs of inflammatory small airway disease and small airway obstruction.

Interstitial abnormalities, which may appear as ground-glass or reticular infiltrates, likely correspond to variable combinations of respiratory bronchiolitis, airspace enlargement with fibrosis, and smoking-related interstitial fibrosis. ${ }^{[9]}$ Pulmonary hypertension can be a complication of advanced COPD and is due to hypoxic vasoconstriction, pulmonary vascular obliteration, sleep apnoea or left heart abnormality. This important comorbidity is a predictor of hospitalisation and death in COPD.$^{[10]}$ Bronchiectasis, which is most often cylindrical in character, is associated with more severe airflow obstruction, and acute exacerbations resulting in hospitalisation and higher mortality. ${ }^{[11]}$
Integration of visual characterisation of emphysema and airway abnormalities in quantitative CT assessment, together with lung function tests, permit categorisation of COPD into distinct structurally and functionally defined subtypes. This will identify significant disease in subjects with mild or absent physiological evidence of airway obstruction and help determine the progression of these specific patterns of disease and possibly predict treatment response. In summary, CT phenotyping may have an important role in therapeutic decision-making and understanding the natural history of COPD.

\section{S Mothilal}

Fellow in Pulmonology, Groote Schuur Hospital and University of Cape Town, South Africa

1. Friedlander AL, Lynch D, Dyar LA, Bowler RP. Phenotypes of chronic obstructive pulmonary disease. COPD 2007;4(4):355-384. http://dx.doi.org/10. 1080/15412550701629663

2. Lynch D, Austin JH, Lynch JC, et al. CT-definable subtypes of chronic obstructive pulmonary disease: A statement of the Fleischner Society. Radiology 2015;277(1):192205. http://dx.doi.org/10.1148/radiol.2015141579

3. Schroeder JD, McKenzie AS, Zach JA, et al. Relationships between airflow obstruction and quantitative CT measurements of emphysema, air trapping, and airways in subjects with and without chronic obstructive pulmonary disease. Am J Roentgenol 2013;201(3):W460-W470. http://dx.doi.org/10.2214/ajr.12.10102

4. Ostridge K, Wilkinson TMA. Present and future utility of computed tomography scanning in the assessment and management of COPD. Eur Respir J 2016;48(1):216228. http://dx.doi.org/10.1183/13993003.00041-2016

5. Fishman A, Martinez F, Naunheim K. A randomized trial comparing lung-volumereduction surgery with medical therapy for severe emphysema. N Engl J Med 2003;348(21):2059-2073. http://dx.doi.org/10.1056/nejmoa030287

6. Johannessen A, Skorge TD, Bottai M, et al. Mortality by level of emphysema and airway wall thickness. Am J Respir Crit Care Med 2013;187(6):602-608. http://dx.doi. org/10.1164/rccm.201209-1722oc

7. Hogg JC, Macklem PT, Thurlbeck WM. Site and nature of airway obstruction in chronic obstructive lung disease. N Engl J Med 1968;278(25):1355-1360. http://dx.doi. org/10.1056/nejm196806202782501

8. Hogg JC, Chu F, Utokaparch S, et al. The nature of small-airway obstruction in chronic obstructive pulmonary disease. N Engl J Med 2004;350(26):2645-2653. http://dx.doi. org/10.1056/nejmoa032158

9. Washko GR, Lynch DA, Matsuoka S, et al. Identification of early interstitial lung disease in smokers from the COPDGene study. Acad Radiol 2010;17(1):48-53. http:// dx.doi.org/10.1016/j.acra.2009.07.016

10. Chaouat A, Naeije R, Weitzenblum E. Pulmonary hypertension in COPD. Eur Respir J 2008;32(5):1371-1385. http://dx.doi.org/10.1183/09031936.00015608

11. Martínez-García MA, Soler-Cataluña JJ, Donat Sanz Y, et al. Factors associated with bronchiectasis in patients with COPD. Chest 2011;140(5):1130-1137. http://dx.doi. org $/ 10.1378 /$ chest. $10-1758$

S Afr Respir J 2016;22(4):106-107. DOI:10.7196/SARJ.2016.v22i4.103 